\title{
Fabrication of Cellulose Based Reinforced Linear Low Density Polyethylene with Polyethylene Terephthalate Composite: Effect of Acacia catechu as Coupling Agent
}

\author{
Lily R. Das',2, Mohammad Zahirul I. Mollah'1, Jahid M. M. Islam¹, Shireen Akhter ${ }^{3}$, \\ Farid Ahmed ${ }^{2}$, Mubarak Ahmad Khan ${ }^{*}$ \\ ${ }^{1}$ Institute of Radiation and Polymer Technology, Atomic Energy Research Establishment, Bangladesh Atomic \\ Energy Commission, Dhaka, Bangladesh \\ ${ }^{2}$ Department of Physics, Jahangirnagar University, Savar, Bangladesh \\ ${ }^{3}$ Material Science Division, Atomic Energy Centre, Bangladesh Atomic Energy Commission, Dhaka, Bangladesh \\ Email: *makhan.inst@gmail.com
}

Received 15 August 2015; accepted 15 November 2015; published 18 November 2015

Copyright (C) 2015 by authors and Scientific Research Publishing Inc.

This work is licensed under the Creative Commons Attribution International License (CC BY). http://creativecommons.org/licenses/by/4.0/

(c) (i) Open Access

\section{Abstract}

Biodegradable reinforced composites are playing a vital role in the variety of application for their outstanding performance. Linear Low Density Polyethylene (LLDPE) and Polyethylene Terephthalate (PET) blends were prepared by twin screw extruder in different composition. The mechanical properties in 10\% PET with LLDPE blend showed the best results where as tensile strength (TS) $9 \mathrm{MPa}$ and percentage elongation at break (\%Eb) 33. Cellulose based reinforced PET + LLDPE composite were prepared by compression molding with the optimized jute content $62 \%$ that revealed the highest mechanical properties. Cellulose based composites treated with Acacia catechu (AC) solutions $(0.1 \%-5 \% \mathrm{w} / \mathrm{v})$ at different soaking time (2- $20 \mathrm{~min}$.) where observed significant improvement of the mechanical properties. Cellulose treated with $0.1 \% \mathrm{AC}$ for 2 minutes soaking time depicted the highest mechanical properties and TS is $115 \%$ higher than untreated. Composite prepared with $0.1 \%$ AC treated showed the best mechanical properties as tensile strength (TS), bending strength (BS), tensile modulus (TM) and bending modulus (BM) were to be $47 \mathrm{MPa}, 39 \mathrm{MPa}, 1220 \mathrm{MPa}$ and $1784 \mathrm{MPa}$ respectively. The properties of TS, BS, TM and $B M$ were improved as $9 \%, 30 \%, 14 \%$ and $34 \%$ respectively, which were better to untreated composite. Electrical properties such as dielectric constant and loss of the treated and untreated composites were found to be higher dielectric constant of treated jute composite than that of untreated samples. Water uptake and soil degradation of untreated and treated composites

${ }^{*}$ Corresponding author.

How to cite this paper: Das, L.R., Mollah, M.Z.I., Islam, J.M.M., Akhter, S., Ahmed, F. and Khan, M.A. (2015) Fabrication of Cellulose Based Reinforced Linear Low Density Polyethylene with Polyethylene Terephthalate Composite: Effect of Acacia catechu as Coupling Agent. Materials Sciences and Applications, 6, 995-1007. http://dx.doi.org/10.4236/msa.2015.611099 
performed in significant study. The effect of AC with cellulose composites has found in remarkable changes in the mechanical properties.

\title{
Keywords
}

\author{
Jute, Cellulose, Composite, Acacia catechu, Properties
}

\section{Introduction}

Fiber reinforced plastic composites played a dominant role for a long time in a variety of applications, due to their high specific strength and modulus while there has been an increasing interest in biodegradable composites reinforced with natural fibers [1] [2]. Natural fibers are usually made of cellulose, hemicelluloses, lignin and pectin with a small quantity of water soluble materials. However, the one of primary disadvantage is poor interfacial adhesion and dispersion in olefinic thermoplastic matrix materials due to hydrophilic character of cellulose [3] [4]. Natural fibers such as jute, hemp, sisal, pine apple, abaca and coir have been studied as reinforcement and filler in composites. Among all the natural fibers, jute appears to be the most useful, economical and exhibits moderately higher mechanical properties. As a natural fiber jute fiber has been traditionally used for making twines, ropes, cords, as packaging material in sack and gunny bags, as carpet-backing and more recently as a geo-textile material. Jute is a commercially available fiber, which is cultivated almost exclusively in Bangladesh and India. It has high cellulose content and low micro-fibril angle which are the desirable properties of a fiber to be used as reinforcement in a polymer matrix [5] [6]. In spite of these above-mentioned advantages, jute fiber like other natural fibers exerts some difficulties while used as reinforcement in non-polar polymer matrices. Being polar and hydrophilic in nature, jute fiber exhibits poor interfacial adhesion with hydrophobic polymer matrices. To overcome these kinds of bottlenecks, many attempts, such as physical and chemical treatments, lead to changes in the surface structure and surface energy of the fibers.

Khoir extract is derived from heartwood of Acacia catechu (Family: Mimosaceae) tree. Acacia catechu is highly valuable for its powerful astringent and antioxidant activities. The chief constituents of the red heartwood are catechin and catechu tannic acid along with small proportion of brown coloring matter. It also contains tannin, flavotannin, gallotannin, phloratannin etc. The catechin is a biologically important polyphenolic compound. Its heart wood extract was used in dyeing, leather tanning and preservative for fishing nets and as a viscosity regulator for oil drilling [7]. Polyethylene terephthalate (PET) and Linear Low Density Polyethylene (LLDPE) were used as a matrix material in this study because they have some excellent characters for composite fabrication. PET a low cost and high performance thermoplastic is widely used as packaging materials, fiber and sheet due to good rigidity, hardness, abrasion resistance, solvent resistance and electric insulation [8] [9]. The majority of the world's PET production is for synthetic fibers (60\%) with bottle production accounting for $30 \%$ of demand. In this experiment, PET granules were blended with LLDPE at different ratios such as (10:90 and 25:75) using Twine Screw Extruder machine. Higher percentage of LLDPE was taken to have a hybrid polymer film having relatively lower melting point (LLDPE is $120^{\circ} \mathrm{C}$ and PET is about $260^{\circ} \mathrm{C}$ ) which will prevent jute fabric to burn during composite fabrication. LLDPE is one of the most important polyolefins that has been extensively studied from both the industry and academic points of view, for its good processability, great recyclability and preferable compatibility with other polyolefins [10] [11].

The investigation has made an effort to modify hessian cloth (cellulose) with Acacia catechu to see the effect of AC on the mechanical and dielectric properties of hessian cloth-reinforced PET + LLDPE composites. The research also involves in determining the degradation characteristics and water uptake of the composite.

\section{Experimental}

\subsection{Materials}

Bleached jute fabrics were collected from Bangladesh Jute Research Institute (BJRI), Dhaka, Bangladesh. Khoir (Acacia catechu) was collected from local market. PET (Polyethylene Terephthalate) and LLDPE (Linear Low Density Polyethylene) granule were purchased from MITSUIPET Company, Thailand and Uniplast Com. Saudi Arab. 


\subsection{Methods}

\subsubsection{Preparation of Polymer Sheet}

Two types of Hybrid polymer sheet (10\% and 25\% PET in LLDPE) was prepared using a Twin Screw Extruder machine (Type-LTE 16-Lab Tech Engineering Company LTD.) by mixing PET and LLDPE granules.

\subsubsection{Surface Pre-Treatment}

Hessian cloths were cut into small pieces $\left(14 \times 20 \mathrm{~cm}^{2}\right)$ and dried in an oven at $100^{\circ} \mathrm{C}$ for about 1 hour to remove moisture. A number of formulations of AC $(0.1 \%-5 \%)$ were prepared in distilled water. Jute fabrics were soaked with these solutions for different time periods (2 - $20 \mathrm{~min})$. Then the jute fabrics were dried again in an oven at $100^{\circ} \mathrm{C}$ for 3-hour and kept in desiccators.

\subsubsection{Fourier Transform Infrared (FTIR)}

FT-IR spectroscopy of the untreated and treated jute fabrics were recorded with a Happ-Ganzel spectrophotometer using the $\mathrm{KBr}$ pellet technique with a resolution of $4 \mathrm{~cm}^{-1}$.

\subsubsection{Thermogravimetric Analysis (TGA)}

TGA analysis of untreated and treated fibers was done using a thermal gravimetric analyzer (TGA-Universal Mode: $\left.\mathrm{V}_{4.5 \mathrm{~A}} \mathrm{TA}\right)$ at heating rate $10^{\circ} \mathrm{C} / \mathrm{min}$ under a constant flow rate $(60 \mathrm{ml} / \mathrm{min})$ of nitrogen.

\subsubsection{Fabrication of Composite}

Composites were prepared by sandwiching pre-weighted four layers of jute fabrics between five layers of preweighted polymer sheets and pressed at $199^{\circ} \mathrm{C}$ for 20 min between two steel plates under a pressure of 5 tons. The composite was cooled in another press machine, then cut into the desired size using band saw and packaged in a polyethylene bag and then kept in the desiccators prior to further testing.

\subsubsection{Mechanical Tests}

The tensile test of the composites were determined using a Universal testing machine (model H $50 \mathrm{KS}-0404$, Hounsfield Series S, UK) gauge length of $20 \mathrm{~mm}$ and crosshead speed of $10 \mathrm{~mm} / \mathrm{min}$. The test was carried out according to DIN 53455 standard method. The bending strength of the composite samples was measured in the same machine with a span length of $40 \mathrm{~mm}$ and cross-head speed of $4 \mathrm{~mm} / \mathrm{min}$ followed by ASTM D 790 standard method.

\subsubsection{Electrical Properties Measurement}

Electrical properties of the composite were carried out by using Wayne Keer Inductance analyzer (3255B). The rectangular shaped samples were polished well to remove any roughness and the two surfaces of each sample were coated with silver paste as contact material for electrical measurement. The dielectric properties, especially the dielectric constant and dielectric loss of both the treated and untreated composites were calculated from the measured capacitance of samples using the relation $\varepsilon=c t / \varepsilon_{0} A$, where $C$ is the capacitance of the sample in vacuum and $\varepsilon_{0}=$ Permittivity of air $\left(8.85 \times 10^{-12}\right), A=$ Area of cross-section of the sample, $t=$ Thickness of the sample.

\subsubsection{Water Uptake Test of the Composite}

Untreated and treated composite samples were immersed in the beaker containing static water bath at room temperature for different time periods (up to 70 mins). Weight of the samples were determined initially then after certain periods of time samples were taken out from the beaker and wiped with tissue papers then took weight again. The weight gained that is, water uptake of the samples was determined by the subtraction from final weight to initial weight.

\subsubsection{Soil Degradation Study}

The composite samples were buried in soil for degradation study. Soil was maintained at $\sim 25 \%$ moisture in weight and samples were buried at a depth of $25 \mathrm{~cm}$. The buried samples were dug out after some time intervals (5 - 30 days) and washed in distilled water, dried in a vacuum oven at $100^{\circ} \mathrm{C}$ until the samples reached a con- 
stant weight and kept at room temperature for at least $24 \mathrm{~h}$. The mechanical properties of the samples were then measured.

\section{Result and Discussion}

\subsection{Effect of PET/LLDPE Blend on the Mechanical Properties}

For mechanical properties improvement higher percentage of LLDPE was taken to have a hybrid polymer film having relatively lower melting point which will prevent jute fabric to burn during composite fabrication. The composition of PET: LLDPE ratio was taken as (10:90) and (25:75) respectively. From the mechanical studied it was obtained the tensile strength of pure PET ( $28 \mathrm{Mpa}$ ) is higher than LLDPE (7 MPa). In the composite of $10 \%$ PET with LLDPE (90\%) showed higher TS (9 MPa) that of PET (25\%) with LLDPE (75\%) where TS is (8 MPa) because at this percentages PET and LLDPE mix properly in the blend. The EB\% was found in highest in pure LLDPE. The TS is increased and the EB \% is decreased accordingly (Figure 1).

\subsection{FT-IR Analysis}

The FTIR spectra of jute fabric in Figure 2(a) showed a long and broad peak at $3406.29 \mathrm{~cm}^{-1}$ indicate the presence of H-bonded $\mathrm{OH}$ groups. A medium band observed at $2902.87 \mathrm{~cm}^{-1}$ indicates the presence of C-H stretching in the fabrics. A very short peak observed at $2129.41 \mathrm{~cm}^{-1}$ indicates the presence of $-\mathrm{C} \equiv \mathrm{C}$ - bond stretching vibration. A small peak observed at $1730.16 \mathrm{~cm}^{-1}$ indicates the presence of $\mathrm{C}=\mathrm{O}$ stretching of unsaturated aldehyde or ketones. Very small two peaks observed at $1629.85 \mathrm{~cm}^{-1}$ and $1597.06 \mathrm{~cm}^{-1}$ indicates the presence of $-\mathrm{C}=\mathrm{C}$-stretching and $\mathrm{N}-\mathrm{H}$ bending respectively. Very short peak observed $1502.55 \mathrm{~cm}^{-1}$ provides the presence of C-C stretching in ring. Another some peaks observed at 1458.16, 1425.40, 1373.32, 1321.24, 1232.51, 1159.22 and $1111.00 \mathrm{~cm}^{-1}$ attributed to the presence of $\mathrm{C}-\mathrm{H}$ bending, rocking, $\mathrm{N}-\mathrm{O}$ symmetric stretching, C-N stretching, C-O stretching in the fabrics [12]. A small and narrow peak observed at $896.90 \mathrm{~cm}^{-1}$ indicates C-H loop aromatics in the ring. The FTIR spectra of Acacia catechu treated jute in Figure 2(b) showed almost similar type of peaks with little bit changes for coupling between cellulose based composite with AC $(0.10 \%)$ within the same region of the frequencies of jute fabric such as at $3421.72,2900.94,2129.41,1735.93,1629.85,1597.06,1506.41,1458.18$, 1425.4, 1375.25, 1321.24, 1226.73, 1155.36, 1111, 1078.21, $1066.64 \mathrm{~cm}^{-1}$ etc. The comparative coupling FTIR spectra of composites showed in Figure 2(c).

\subsection{TGA Analysis of Fibers}

Thermal gravimetric analysis (TGA) was used to measure the weight loss of fibers as a function of rising temperature. The weight loss in fibers occurs due to the decomposition of cellulose, hemicelluloses and lignin

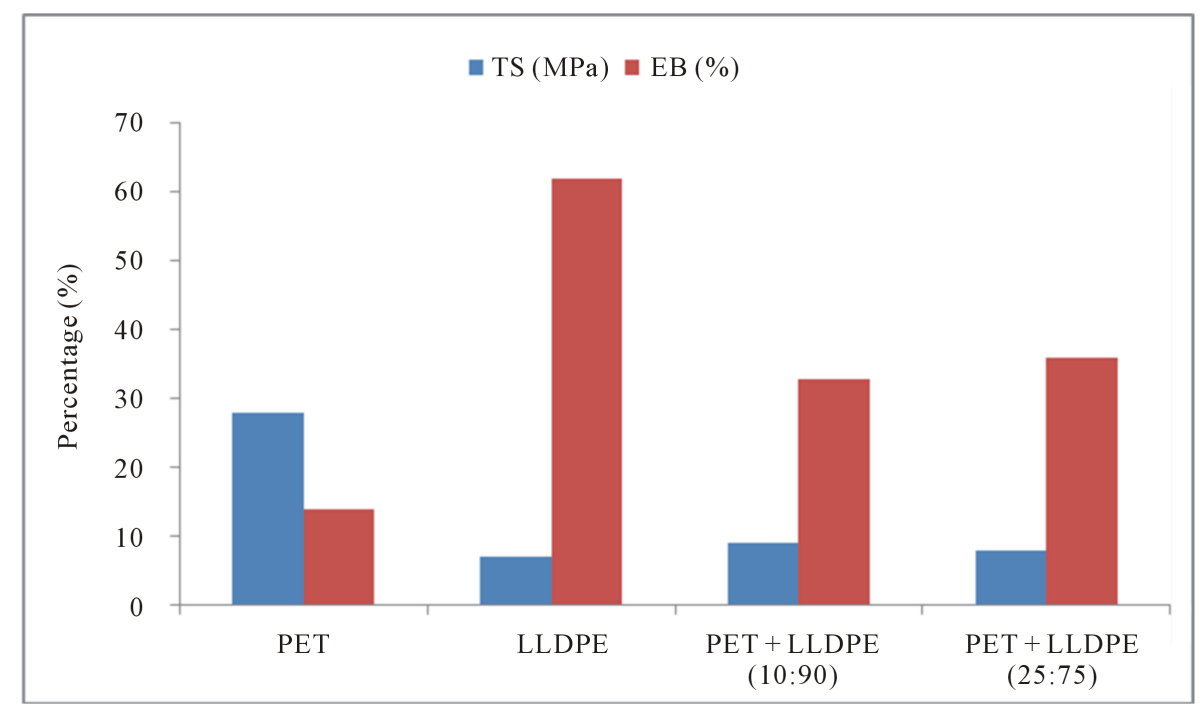

Figure 1. Effect of PET + LLDPE blend on the mechanical properties. 


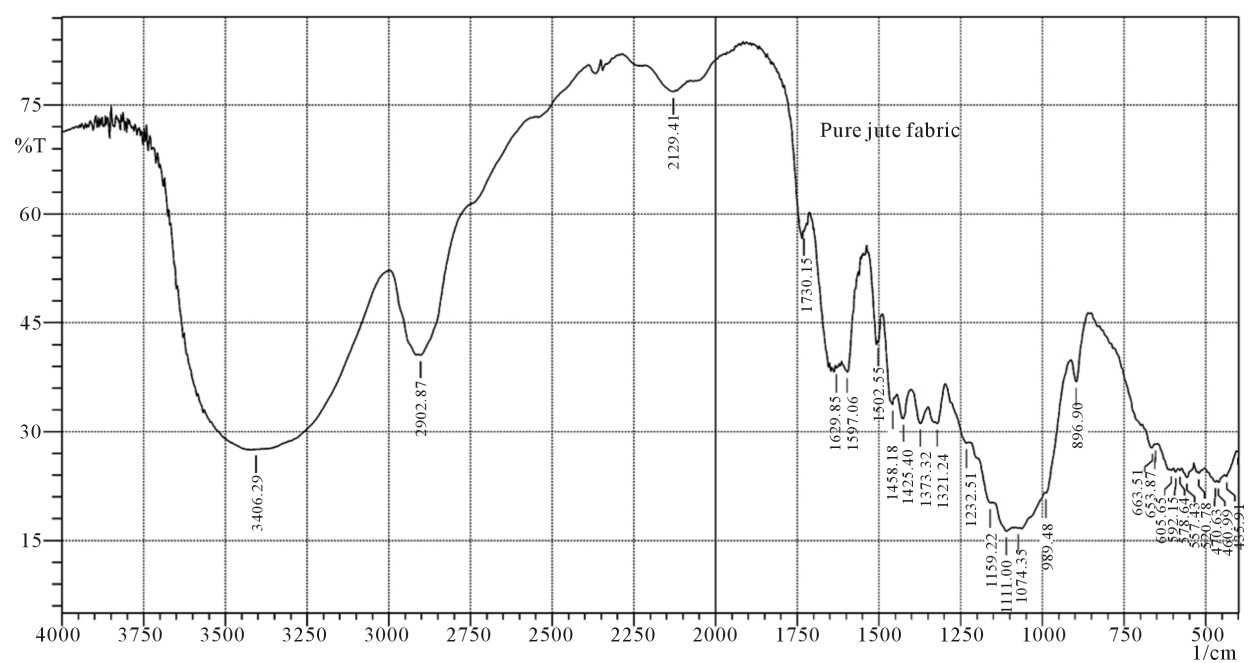

(a)

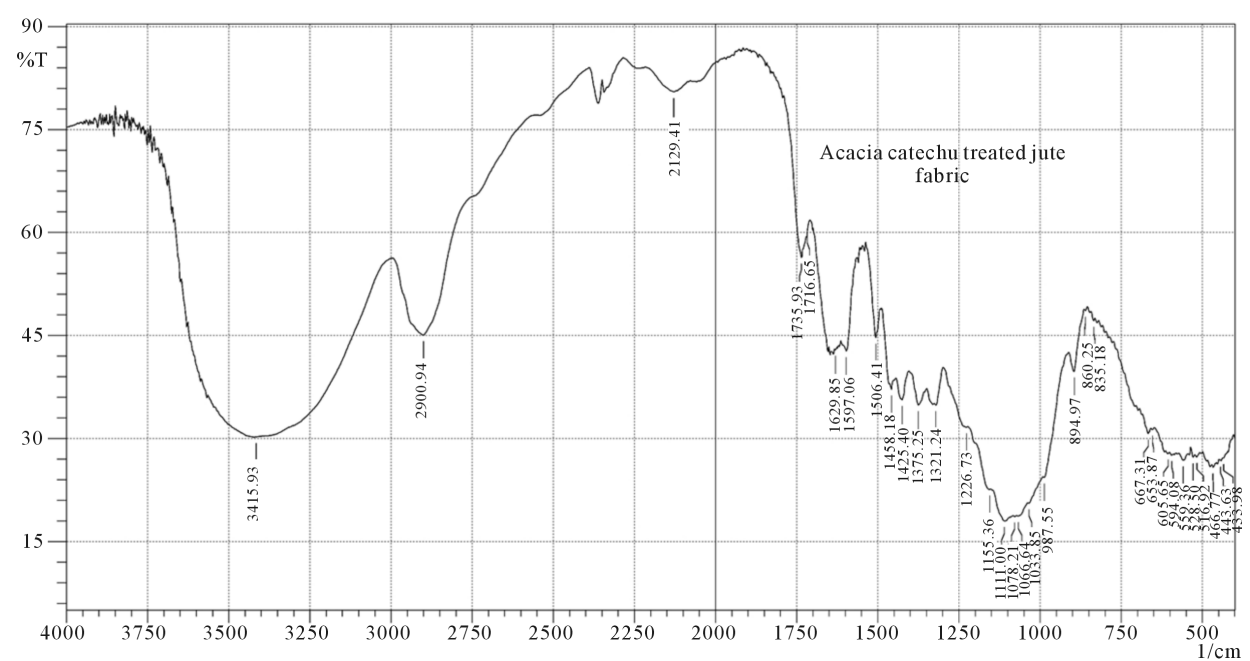

(b)

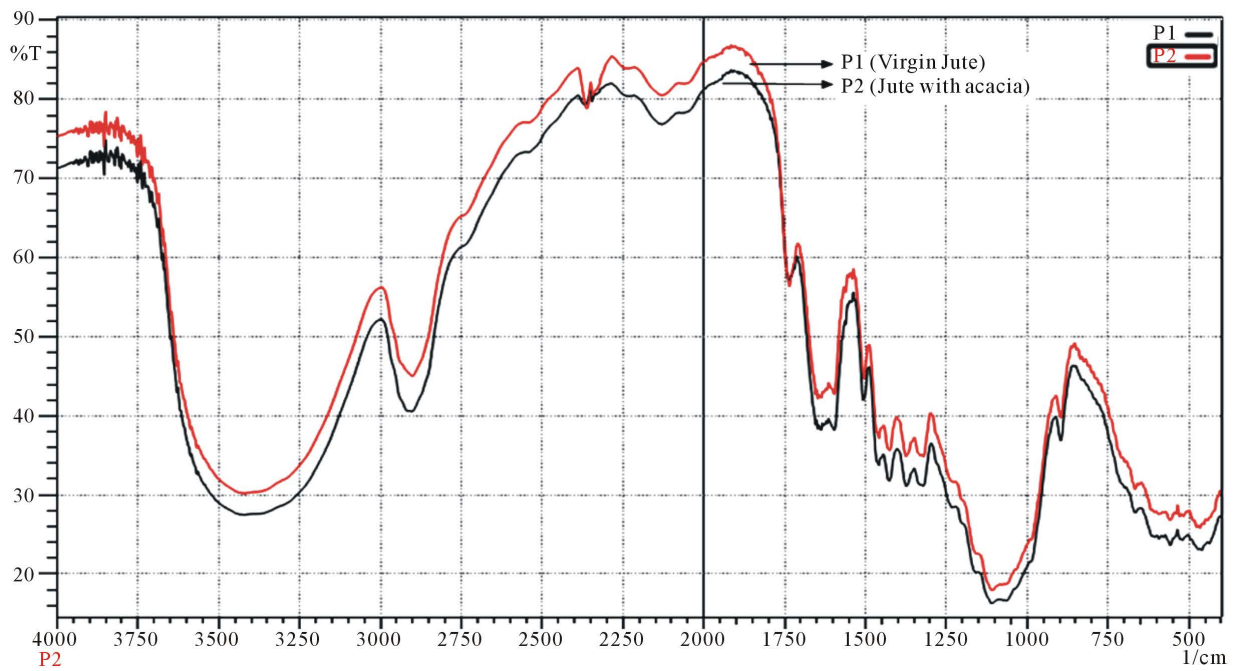

(c)

Figure 2. (a) FT-IR of untreated jute fabric; (b) FT-IR of AC treated jute fabric; (c) Comparative peak study of treated and untreated composite with $0.1 \%$ AC. 
constituents during heating. Higher decomposition temperature gives greater thermal stability [13]. From Figure 3 it can be observed that, there are three stages of weight loss occurred as temperature increased. The first stage of weight loss was observed between $25^{\circ} \mathrm{C}-173^{\circ} \mathrm{C}$, which was correspondence to the release of moisture content by the fiber. The second stage of weight loss occurred within the temperature between $200^{\circ} \mathrm{C}-345^{\circ} \mathrm{C}$, which was related to the degradation of lignin and hemicelluloses. The last stage of weight loss occurred between the temperature of $345^{\circ} \mathrm{C}-500^{\circ} \mathrm{C}$, indicated the degradation of cellulose and other cellulosic matters from the fiber [14]. It also observed that, untreated fiber degrade faster than the treated fibers in the second stage of fiber degradation process. From the results, it can be stated that hemicelluloses and lignin constituents were partially removed from the treated fibers which enhance thermal stability.

\subsection{Effect of Jute Content on the Mechanical Properties of the Composite}

Effect of jute content on the mechanical properties of jute composite was measured and the results are presented in Figure 4(a) and Figure 4(b). The TS and BS of the composites were found to increase on increasing the percentage of jute content in the composite. The highest TS and the BS at $62 \%$ jute content were found to be 43 MPa and 23MPa respectively. The TM and BM of the composite also followed the same way like TS and BS and the effect of fiber content on elongation at break (\% Eb) of the composite is shown in Figure 4(a). The highest TM and BM of the composites (62\%) were found to be1050 MPa and $1170 \mathrm{MPa}$ respectively [Figure 4(b)]. At high levels of fiber content, poor wetability of matrix and improper orientation of fiber is found in the matrix material. This may cause decrease in the mechanical properties of the composite above $62 \%$ jute.

So it is clear that $62 \%$ jute content composite showed the best mechanical properties and this was considered as the optimized content of jute. The influence of jute content on mechanical properties of composites may be explained by the homogeneity of fiber in composite and wet ability of the matrix. Owing to the lower level of the fiber in the matrix, non-homogeneity of the fiber is observed in the composite material. As a result, proper load transfer is not possible by the composites. Fiber matrix adhesion is the key to a strong interface. Optimum adhesion between fiber and matrix can be achieved by maximizing wetting tension. Wetting tension can be maximized by maximizing the physical interactions at the molecular level between matrix and fiber and spontaneous wetting of the fiber surface with liquid matrix in order to maximize the flow density at the interface [15].

\subsection{Effect of AC on Jute Fabric and Composite}

Hessian cloths were soaked in the AC solution for different concentrations ( $0.1 \%$ to $5.0 \%)$ with different soaking time (2 - $20 \mathrm{~min}$.). The results of TS of jute fabrics with respect to different AC concentrations against

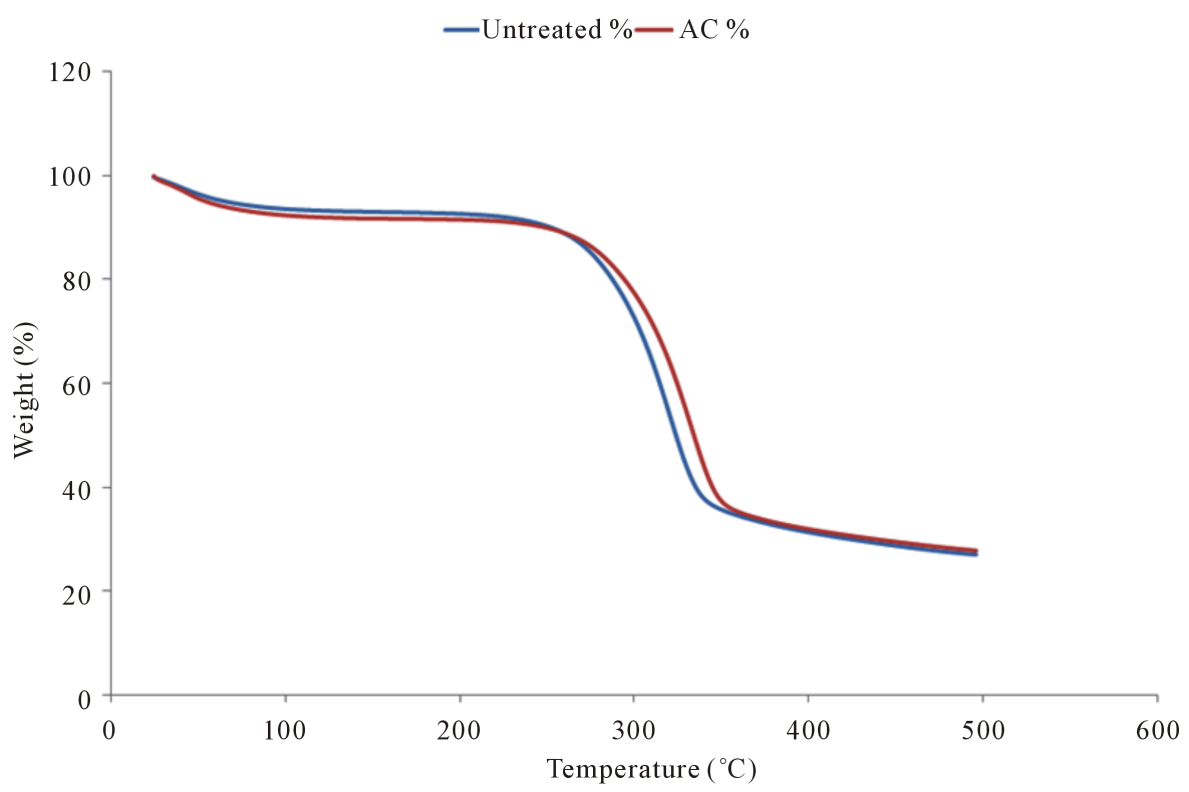

Figure 3. TGA analysis of untreated and AC treated jute fabric. 


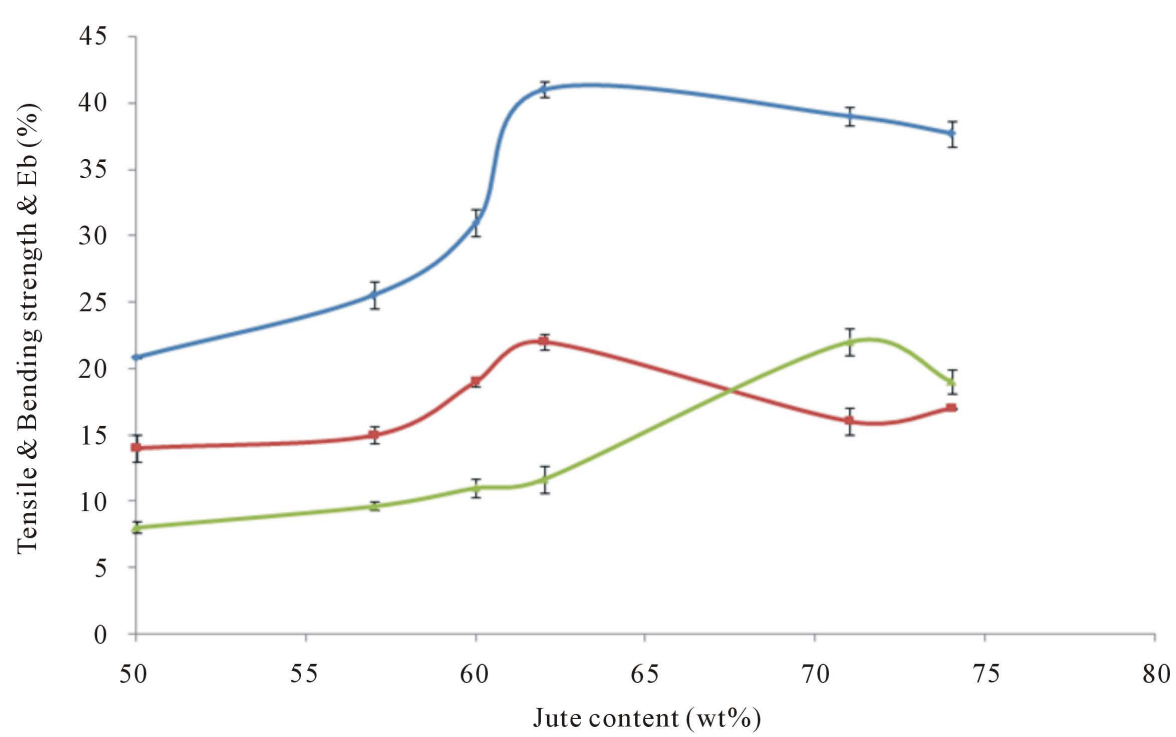

(a)

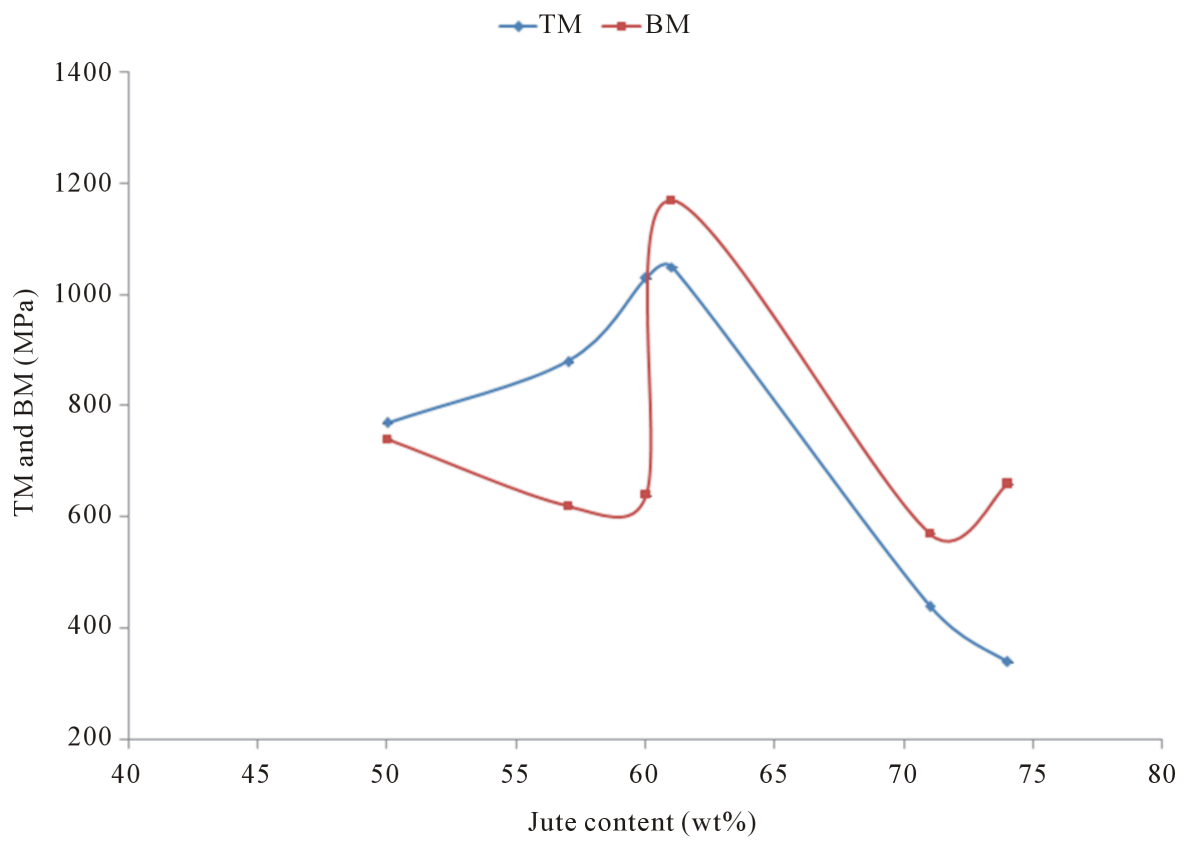

(b)

Figure 4. (a) Effect of jute content (wt \%) on the strength of untreated jute-based composites; (b) Effect of jute content (wt \%) on the modulus of untreated jute-based composite.

different soaking times are presented in Figure 5. It has been observed that TS is higher for $0.1 \%$ AC extract and for 2 min soaking time. But TS of hessian cloth decrease with the increase of soaking time and concentration of AC extracts. The highest TS (24 MPa) was for $0.1 \%$ AC extract and for 2 min soaking time. The TS is $115 \%$ higher compared to untreated hessian cloth. For $0.5 \%$ solution of AC extract the TS increased up to 10 min soaking time and then gradually decrease. The maximum TM is $368 \mathrm{MPa}$ for $1 \%$ AC extract. M. Naznin et.al found that Polyphenolic compound of AC extract fit into the changes in tensile properties of Starch/PVA Film and establish hydrogen bonding with $\mathrm{OH}$ groups of St/PVA [16]. So there may be a hydrogen bonding with 


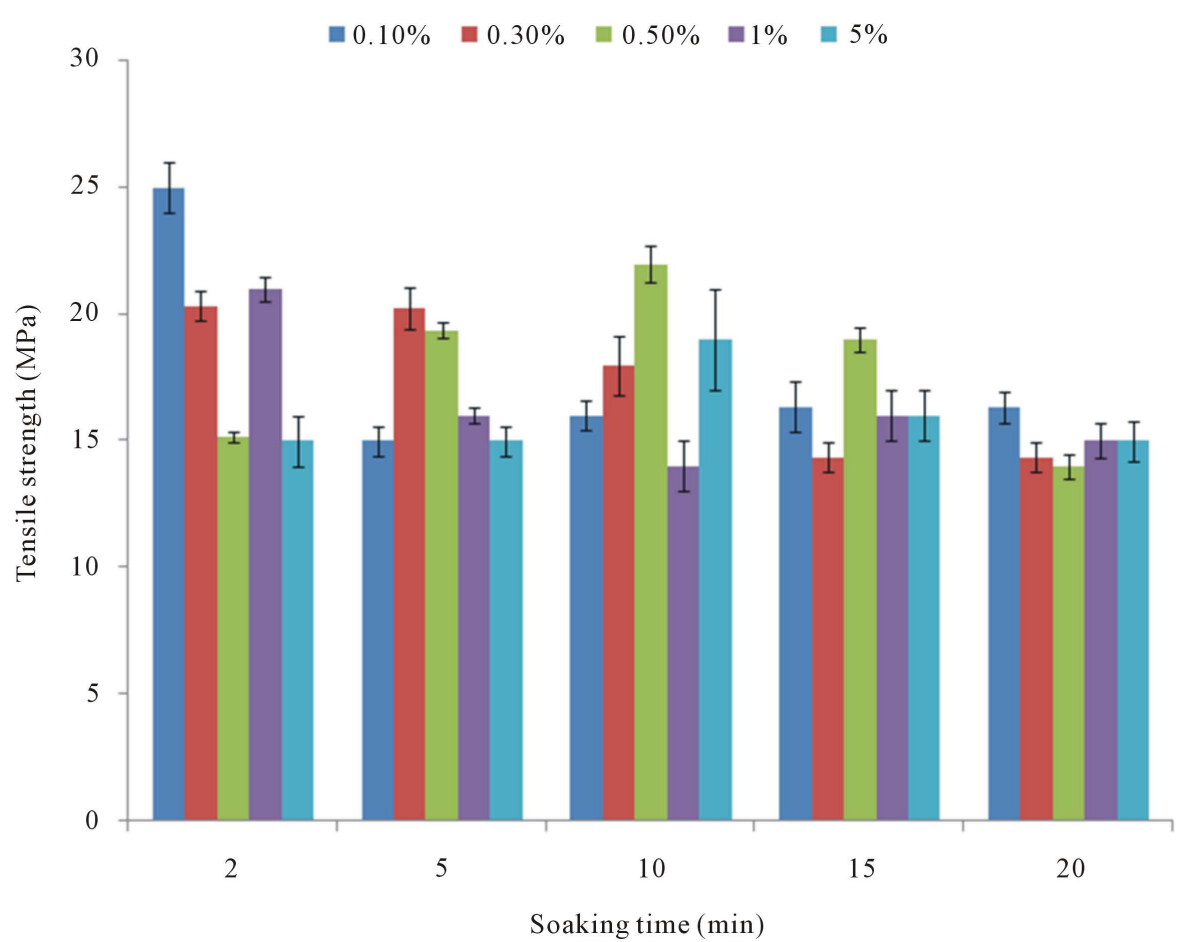

(a)

$=0.10 \%=0.30 \%=0.50 \%=1 \%=5 \%$

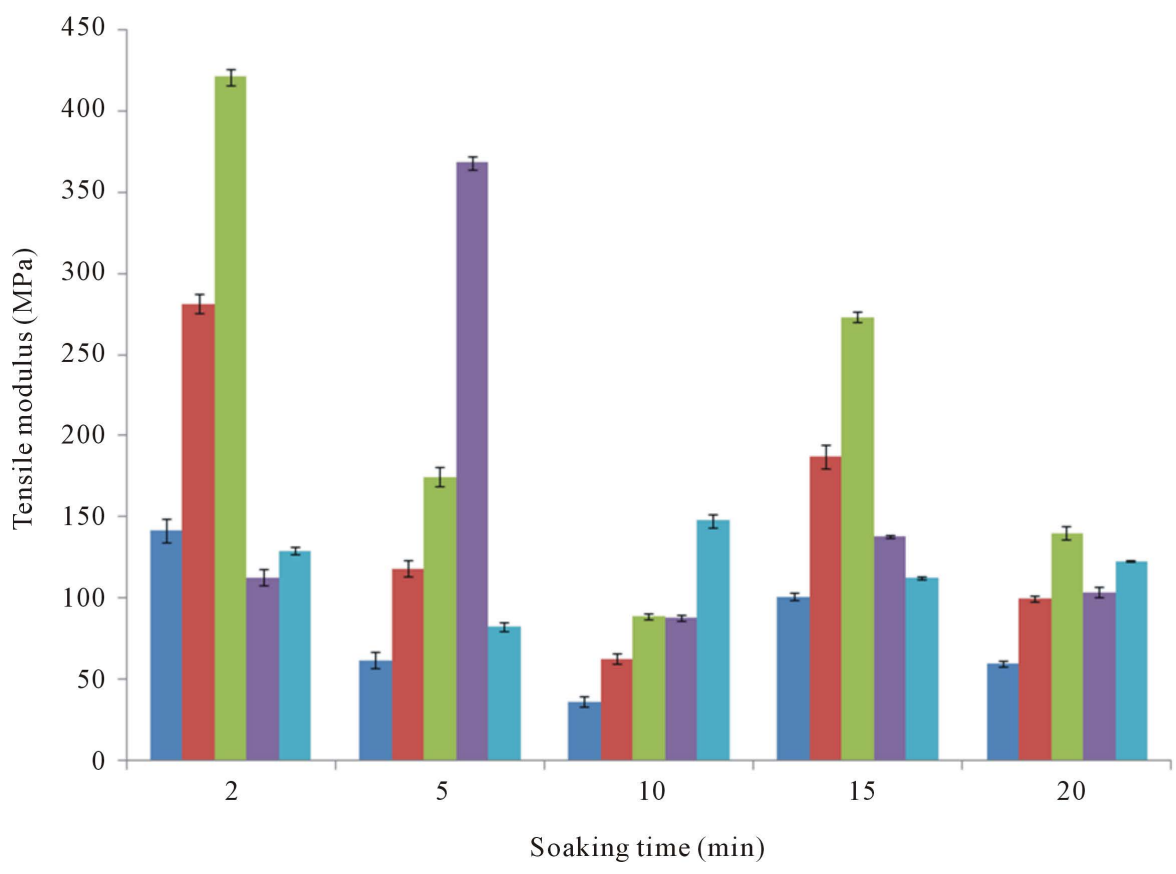

(b)

Figure 5. (a) Effect of AC on Tensile strength of jute fabric; (b) Effect of AC on modulus of jute fabric.

$\mathrm{OH}$ group of Jute fabrics. Changes in mechanical properties as affected by polyphenolic compounds were also observed for other biopolymeric films [17] [18].

However, after a certain value with the increase of soaking time the TS and TM of the hessian cloth gradually 
decreased (Figure 5(a) and Figure 5(b)). This sharp decrease of TS and TM at higher soaking time may be due to shrinking of compactness of the jute fabrics components. The mechanical properties of the treated hessian cloth based composites were found to be higher than those of the untreated hessian cloth based composites. Among all the formulations $0.1 \%$ AC treated hessian cloth based composite showed the highest tensile strength (Table 1). It was found that the maximum TS, BS, TM, BM of jute/hybrid polymer composite were found to be $47 \mathrm{MPa}, 39 \mathrm{MPa}, 1220 \mathrm{MPa}, 1784 \mathrm{MPa}$ for $0.1 \%$ AC solution and for 2 min soaking time. It has been seen that AC extract treated jute-based composite TS and BS is $9 \%$ and $70 \%$ higher than that of untreated composite. At higher AC extract concentration the Jute fabrics become too sticky and as a result the adhesion between the fibers and matrix may not be so good. Probably this is the cause of low TS and BS of the AC extract treated composite as found in the experiment. The TM, BM also followed the same trend.

\subsection{Frequency Dependence Electrical Properties of the Composite}

Dielectric constant decrease with increasing frequency, so frequency has an important influence on dielectric properties. This was because at high frequencies, the rotation motion of the polar molecules of dielectric is not sufficiently rapid for attain of equilibrium with the field [19]. Figure 6(a) shows the variation of dielectric properties with frequency from $8 \mathrm{KHz}$ to $500 \mathrm{KHz}$ at room temperature. It has been observed that the dielectric constant decreased from $8 \mathrm{KHz}$ to $250 \mathrm{KHz}$ for untreated sample and $8 \mathrm{KHz}$ to $200 \mathrm{KHz}$ for treated sample with increasing frequency for all the specimens exhibiting a normal dielectric behavior of materials, which may be due to the interfacial polarization as predicted by Maxwell and Wagner [20]. The dielectric constant of polymeric material depends on interfacial, dipole, electronic and atomic polarization [21]. The dielectric constant after decreasing reached a constant value and finally become almost constant. It was found that all the samples have higher dielectric constant at low frequency. The highest dielectric constant for $8 \mathrm{KHz}$ is 8.98 for untreated sample and 20.08 for treated sample. This high value of dielectric constant at lower frequency region is due to the Maxwell-Wagner interfacial type of polarization [20] for the inhomogeneous double layer dielectric structure, which is in agreement with Koops phenomenological theory [22]. The dipoles lime up in the field direction at low frequency but at high frequencies when the field is in reverse direction they take reverse direction. This was because at high frequencies, the rotational motion of the polar molecules of dielectric is not sufficiently rapid for attain of equilibrium with the field [19]. Owing to their inertia, the dipoles took a certain time to be in reverse direction, this is called as relaxation time. When the frequency is high the dipole will follow the changes of the field and the dielectric constant will decrease. In Figure 6(b) we found the variation of dielectric loss factor from $8 \mathrm{KHz}$ to $150 \mathrm{KHz}$ for untreated sample and from $8 \mathrm{KHz}$ to $200 \mathrm{KHz}$ for treated sample. In the reverse direction of field the internal friction of the dipoles are so high that the dielectric loss factor decrease. The dielectric Loss factor varied from $8 \mathrm{KHz}$ to $250 \mathrm{KHz}$ and become almost constant (Figure 6(b)).

\subsection{Water Uptake}

Water uptakes of untreated and treated hybrid composite were measured by soaking the samples in a glass beaker containing static water at room temperature $\left(25^{\circ} \mathrm{C}\right)$ for $70 \mathrm{~min}$. The percent of water uptake of the control and AC treated jute fabrics-(PET+LLDPE) composite was measured with different time intervals (min). The results were presented in Figure 7. It is observed that water absorption of control composite is higher than that of AC treated jute composites. In treated composite, the better fiber-matrix adhesion might be responsible for the lower tendency of water uptake compared to control composite. It is also mentionable that at the beginning water absorption for both untreated and treated composite is very rapid because they played as osmotic behavior. After 30 minutes of water soaking, percent of water gain of control composite become lower. This phenomenon is also observed for AC treated composite. At static condition, fibers get saturated with water molecules and can no more gain water from the surroundings and finally decreased because they played as reverse osmotic behavior.

\subsection{Degradation in Soil}

Both untreated and AC extract treated composite samples were immersed in soil for about 30 days. The loss of TS was periodically measured and the results are presented in Figure 8 with respect to degradation time. The loss of TS of untreated was higher than that of treated sample. It was observed that the TS loss increased with increasing degradation time (days). 
Table 1. Optimized condition of $0.1 \%$ AC treated composite.

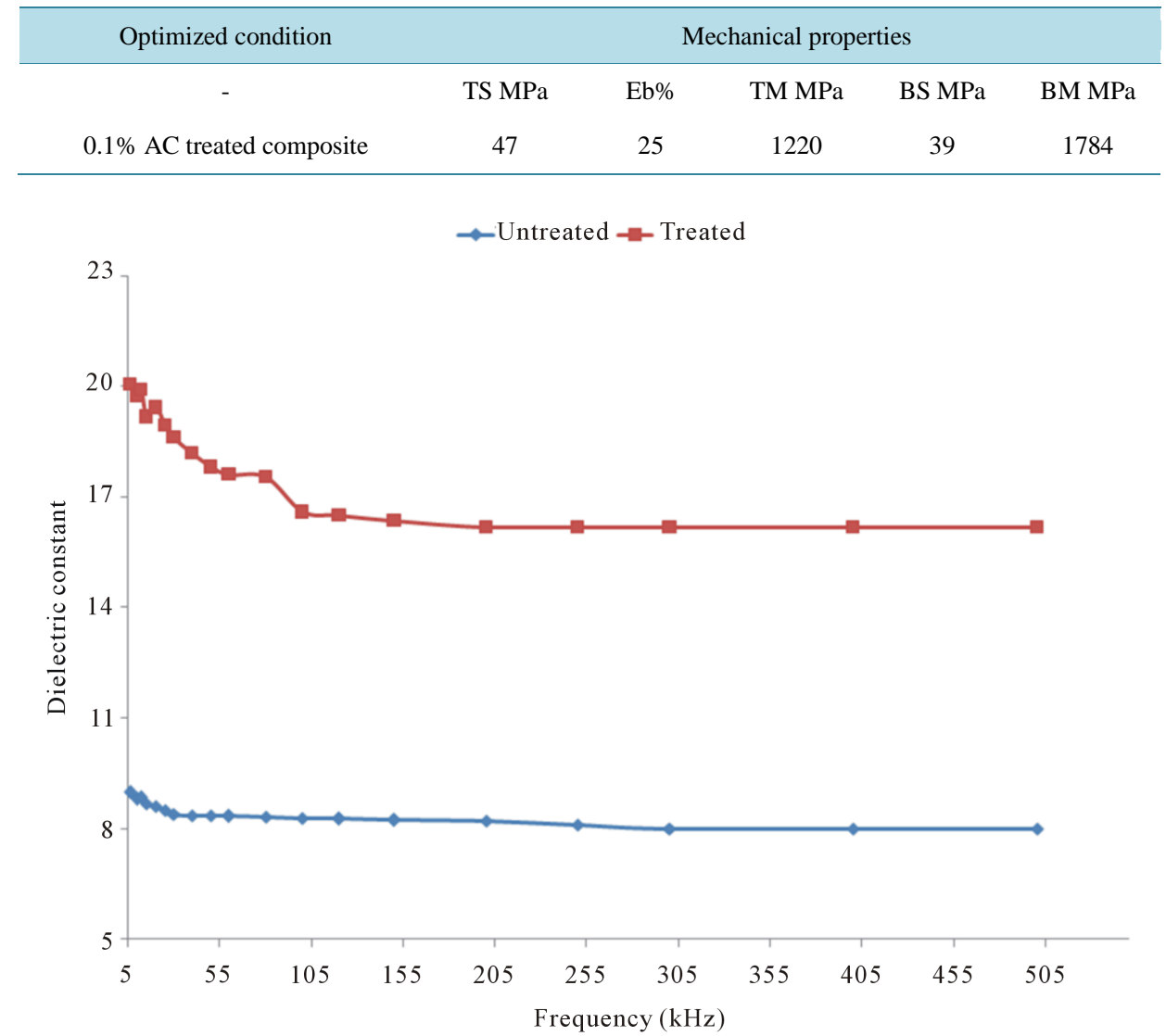

(a)

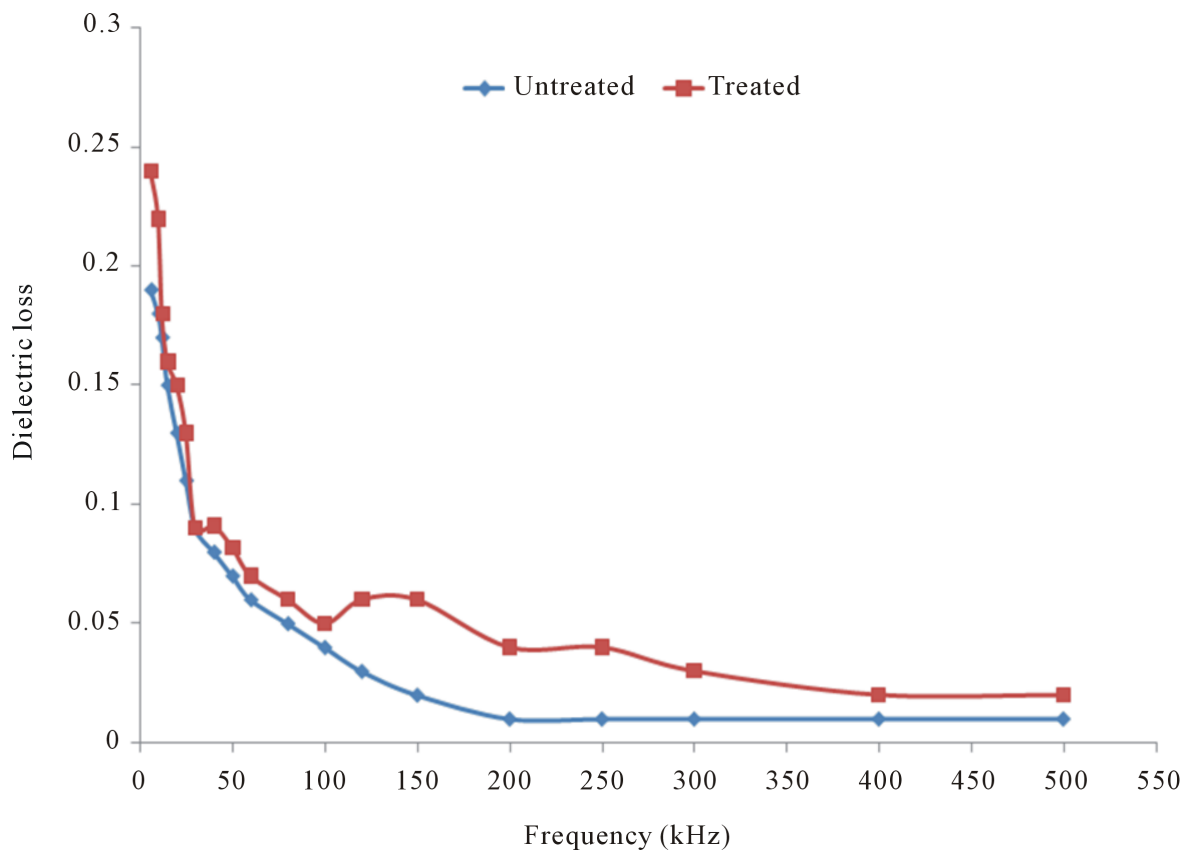

(b)

Figure 6. (a) Variation of dielectric constant with frequency for untreated and AC treated composite; (b) Variation of dielectric loss with frequency for untreated and treated composites. 


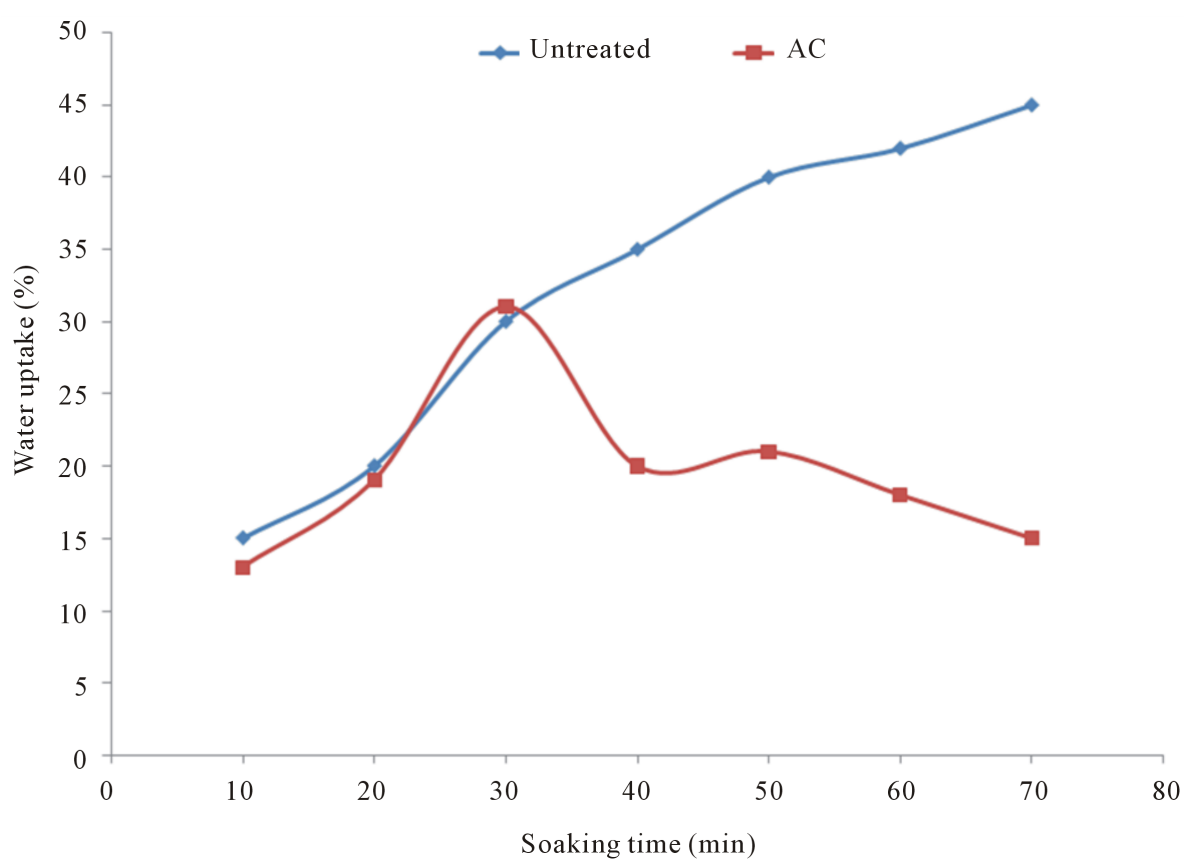

Figure 7. Water uptake of untreated and treated composites against soaking time.

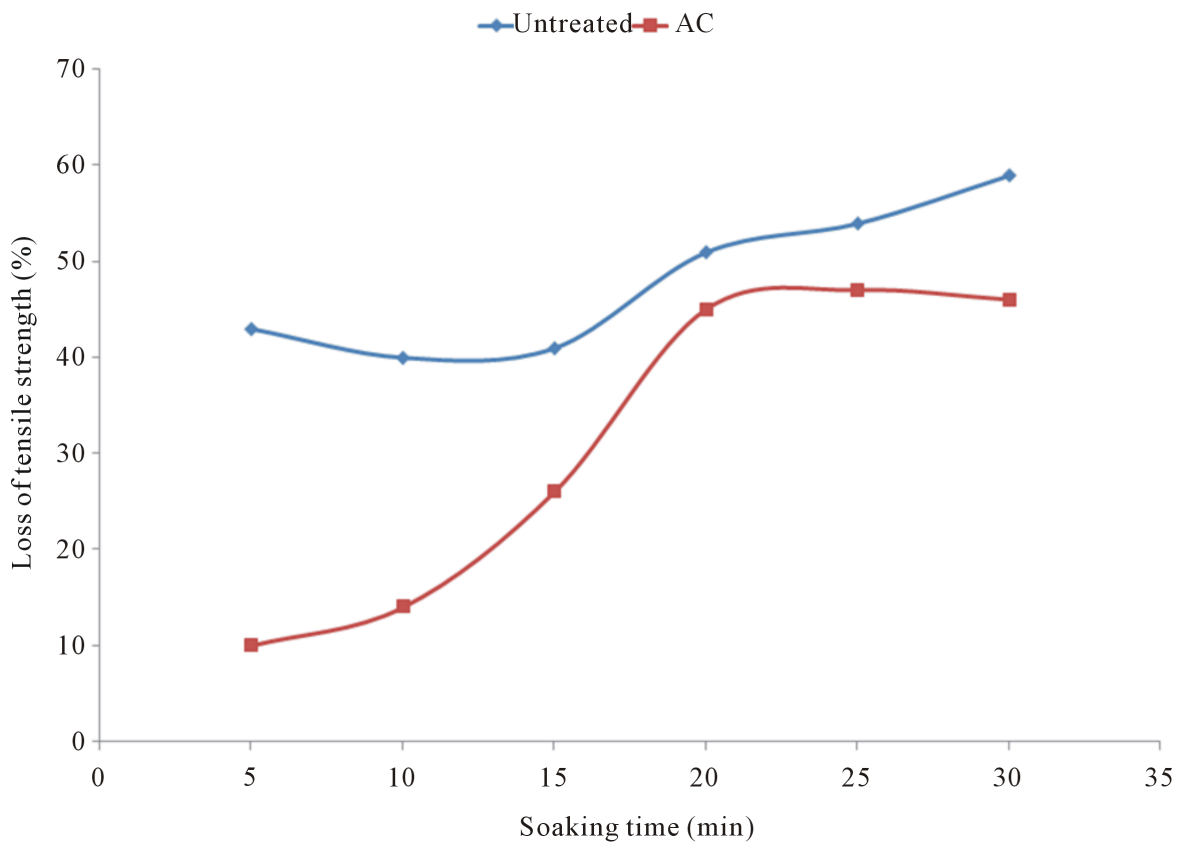

Figure 8. Loss of tensile strength against degradation time because of soil degradation.

\section{Conclusion}

Investigation showed that the mechanical properties of jute fabrics reinforced polymer composite showed a good result. Jute fabrics were treated with AC extracts in order to improve mechanical properties. The highest TS for 0.1\% AC treated jute fabrics were $24 \mathrm{MPa}$ which was increased about $115 \%$ compared to untreated jute fabric. Again jute/hybrid matrix composites were prepared with $0.1 \%$ AC treated jute fabric. The highest TS, BS were 47, $39 \mathrm{MPa}$, and TM, BM were 1220 and $1784 \mathrm{MPa}$ respectively which were increased about $9 \%, 70 \%, 16 \%$ and 52\% respectively. The FT-IR analysis showed that there ocurred no chemical reaction between AC and jute 
fiber. From TGA analysis, it was found that AC treated jute fabric was more thermally stable than untreated jute fabric. Water uptake behavior of the treated sample showed a lower trend compared to untreated sample. The dielectric constant and dielectric loss factor both decrease with increasing frequency. The dielectric constant and dielectric loss factor are both higher for treated composite. It can be concluded that with efficient and continual research there will be good possibility and better future for polymer reinforced composites for suitable electrical applications such as terminals, connectors, switches, circuit boards etc.

\section{References}

[1] Shibata, M., Takachiyo, K., Ozawa, K., Yosomiya, R. and Takeshi, H. (2002) Biodegradable Polyester Composites Reinforced with Short Abaca Fiber. Journal of Applied Polymer Science, 85, 129-138. http://dx.doi.org/10.1002/app.10665

[2] Mizanur, R.M., Malik, A.K. and Khan, M.A. (2007) Influences of Various Surface Pretreatments on the Mechanical and Degradable Properties of Photografted Oil Palm Fibers. Journal of Applied Polymer Science, 105, 3077-3086. http://dx.doi.org/10.1002/app.26481

[3] Reddy, N. and Yang, Y. (2006) Properties of High-Quality Long Natural Cellulose Fibers from Rice Straw. Journal of Agricultural and Food Chemistry, 54, 8077-8081. http://dx.doi.org/10.1021/jf0617723

[4] Mwaikambo, L.Y. and Ansell, M.P. (2002) Chemical Modification of Hemp, Sisal, Jute, and Kapok Fibers by Alkalization. Journal of Applied Polymer Science, 84, 2222-2234. http://dx.doi.org/10.1002/app.10460

[5] Khan, M.A., Hassan, M.M. and Drzal, L.T. (2005) Effect of 2-Hydrixyethyl Methacrylate (HEMA) on the Mechanical and Thermal Properties of Jute/Polycarbonate Composites. Composite A: Applied Science and Manufacturing, 36, 71-81.

[6] Bogoeva-Gaceva, G., Avella, M., Malinconico, M., Buzarovska, A., Grozdanov, A., Gentile, G. and Errico, M.E. (2007) Natural Fiber Eco-Composites. Polymer Composites, 28, 98-107. http://dx.doi.org/10.1002/pc.20270

[7] Hye, M.A., Taher, M.A., Ali, M.Y., Ali, M.U. and Shahed, Z. (2009) Isolation of (+)-Catechin from Acacia catechu (Cutch Tree) by a Convenient Method. Journal of Scientific Research, 1, 300-305. http://banglajol.info/index.php/JSR/article/viewArticle/1635

[8] Zhang, H., Zhang, Y., Guo, W. and Wu, C. (2008) Thermal Properties and Morphology of Recycled Poly(ethylene terephthalate)/Maleic Anhydride Grafted Linear Low-Density Polyethylene Blends. Journal of Applied Polymer Science, 109, 3546-3553. http://dx.doi.org/10.1002/app.28456

[9] Kagan, V.A., Palley, I. and Jia, N. (2004) Plastics Part Design: Low Cycle Fatigue Strength of Glass-Fiber-Reinforced Polyethylene Terephthalate (PET). Journal of Reinforced Plastics and Composites, 23, 1607-1614. http://dx.doi.org/10.1177/0731684404039784

[10] Rebeiz, K.S. and Fowler, D.W. (1994) Flexural Properties of Reinforced Polyester Concrete Made with Recycled PET. Journal of Reinforced Plastics and Composites, 13, 895-907. http://dx.doi.org/10.1177/073168449401301004

[11] Hasan, M.M., Islam, M.R. and Khan, M.A. (2003) Improvement of Physico-Mechanical Properties of Jute Yarn by Photografting with 3-(Trimethoxysilyl) Propylmethacrylate. Journal of Adhesion Science and Technology, 17, 737-750. http://dx.doi.org/10.1163/156856103321340840

[12] Silverstein, R.M., Bassler, G.C. and Morrill, T.C. (1981) Spectrometric Identific Action of Organic Compounds. 4th Edition, John Wiley and Sons, New York.

[13] Menczel, J.D., Judovits, L., Prime, R.B., Bair, H.E., Readin, M. and Swier, S. (2009) Differential Scanning Calorimetry(DSC). In: Menczel, J.D. and Prime, R.B., Eds., Thermal Analysis of Polymers. Fundamentals and Applications, Wiley, San Jose, 7-239.

[14] Ball, R., Melntosh, A. and Brindley, J. (2004) Feedback Processes in Cellulose Thermal Decomposition: Implications for Fire-Retarding Strategies and Treatments. Combustion Theory and Modeling, 8, 281-291. http://dx.doi.org/10.1088/1364-7830/8/2/005

[15] Connor, M., Bidaux, J.E. and Manson, J.A.E. (1997) A Criterion for Optimum Adhesion Applied to Fibre Reinforced Composites. Journal of Material Science, 32, 5059-5067.

[16] Naznin, M., Abedin, M.Z., Khan, M.A. and Gafur, M.A. (2012) International Scholarly Research Network. ISRN Polymer Science, 2012, Article ID: 348685.

[17] Gomez-Estuca, J., Gimenz, B., Mentro, P. and Gomez-Guillen, M.C. (2009) Incorporation of Antioxidant Borage Extract into Edible Films Based on Sole Skin Gelatin or a Commercial Fish Gelatin. Journal of Food Engineering, 92, 7885. http://dx.doi.org/10.1016/j.jfoodeng.2008.10.024

[18] Gomez-Guillein, M.C., Ihl, M., Bifani, V., Silva, A. and Montero, P. (2007) Edible Films Made from Tuna-Fish Gelatin with Antioxidant Extracts of Two Different Murta Ecotypes Leaves (Ugni molinae Turcz). Food Hydrocolloids, 21, 1133-1143. http://dx.doi.org/10.1016/j.foodhyd.2006.08.006 
[19] Smyth, C. (1956) Dielectric Behavior and Structure, McGraw Hill, Oxford, 53.

[20] Wagner, K.W. (1913) Zur Theorie der Unvollkommenen Dielekrika. Annalen der Physik, 345, 817-855. http://dx.doi.org/10.1002/andp.19133450502

[21] Jayamoland, G., Bhagwan, S.S. and Thomas, S. (1997) Electrical Properties of Pineapple Fibre Reinforced Polyethylene Composites. Journal of Polymer Engineering, 17, 383-404.

[22] Koops, C.G. (1951) On the Dispersion of Resistivity and Dielectric Constant of some Semiconductor at Audio Frequencies. Physical Review, 83, 121-124. http://dx.doi.org/10.1103/PhysRev.83.121 